\title{
PRENSA, LITERATURA Y COMBATE IDEOLÓGICO: LA POESÍA EN EL DIARIO LA LIBERTAD DURANTE LA GUERRA CIVIL ESPAÑOLA
}

NoRberto Pérez Garcla

Durante la guerra civil la prensa española experimenta un gran desarrollo que, al tiempo que le hace asumir y consolidar funciones originadas en la etapa republicana, origina otras nuevas. Estas nuevas funciones deben ser atribuidas sobre todo a los periódicos militares ${ }^{1}$ pero también a las publicaciones de la retaguardia, sean perídicos, doctrinales e ideológicos, órganos de expresión de fábricas o empresas o diarios nacionales de gran implantación ${ }^{2}$.

Uno de los diarios más representativos de este periodo es La libertad, periódico de sólida implantación en la prensa del periodo, publicado desde 1919 y con 5920 números hasta que deja de editarse al final de la guerra civil. Es uno de los prototipos españoles del diario modemo, con un contenido variado y de enfoque diverso.

De orientación izquierdista moderada, La libertad va a reflejar entre 1936 y 1939 los cambios de todo tipo que se producen en estos años, no sólo porque

I Cfr. Núnez Díaz-Balart, M.: La prensa de guerra en la zona republicana durante la guerra civil española (1936-1939), Madrid, Ediciones de la Torre, 1992.

2 Cfr. Salailn, S.: La poesla de la guerra de España, Madrid, Castalia, 1985, pp. 50 y ss.; y del mismo autor «f́ndice de la prensa republicana de la guerra de España, Estudios de Historia Social, 24-25 (1984), pp. 475-544. 
vaya informando cotidianamente de los sucesos del momento sino, sobre todo, porque las propias circunstancias históricas tienen una repercusión directa sobre el diario.

Esto último se observa muy bien en el cambio en el propio subtítulo del periódico: al lema primitivo, Diario republicano independiente, se le añade la matización de Órgano de expresión del Frente Popular. Y, durante la contienda, su director, Antonio de Hermosilla, es detenido en Ávila y se le somete a juicio sumarísimo, siendo sustituido posteriormente por Antonio de Lezama.

La escasez de papel afecta indudablemente al perídico, como a toda la prensa republicana del momento: la calidad del papel se va deteriorando poco a poco, disminuye gradualmente el número de páginas (a comienzos de la guerra constaba de doce páginas pero muy pronto el número se vuelve fluctuante hasta fijarse, desde septiembre de 1936, en cuatro, para quedar reducido a una sola hoja en 1938 y 1939), se altera el color (blanco y salmón alternan) y varía el formato (mucho más pequeño entre el 24 de noviembre de 1936 y el 24 de enero de 1937) y, en fin, deja de publicarse algunos días.

Estas dificultades de publicación tienen dos claras manifestaciones dentro del mismo diario: la abundancia de artículos sobre las dificultades de la prensa (sobre todo a partir de 1937) y la poca calidad de los medios técnicos, como muestran los abundantes artículos cortados arbitrariamente por espacios en blanco.

Y la guerra provoca la propia destrucción de las prensas del diario: durante el asedio y defensa de Madrid, en un bombardeo a la capital, el 17 de noviembre de 1936, la redacción central del periódico es alcanzada y destruida. Como consecuencia, durante dos meses, para salir a la calle, se tienen que utilizar las prensas de $A B C$, lo que ocasiona su variación en tamaño y formato.

Pero la guerra deja también sus huellas, como es lógico, en el mismo contenido de La libertad. El perí́dico, en los primeros días del levantamiento militar, cuando todavía no se ha tomado conciencia clara de la gravísima situación en que se encontraba el país, continúa con sus secciones habituales de los meses y años anteriores: editorial, «Coplas del día», información sobre bolsas y finanzas, sucesos, información política, teatral, cinematográfica, cómics, deportes, reseña de libros, peticiones variadas y anuncios comerciales. En los primeros días de la guerra y en la parte inferior del diario se publican diversas entregas del folletín de Dumas Los mohicanos de París.

La guerra hace cambiar las secciones: desaparecen, o quedan reducidas al mínimo, la mayoría de aquellas (salvo los editoriales, la sección poética o la información teatral; la información deportiva queda muy espaciada y se utiliza, a veces, con fines políticos) y se crean otras nuevas en concordancia con la situación histórica. 
Prima ahora, sobre todo, la información sobre los distintos frentes de guerra, acompañada de material gráfico, en secciones como $\ll E l$ desarrollo de las operaciones», «Impresión de la jornada», «Perfiles de la ciudad en guerra», «Madrid en guerra», «Evacuación de Madrid» y otras en las que se exalta a los héroes republicanos («Figuras de la contienda» 0 «Titanes de la República») o se realiza una semblanza de líderes políticos o sindicales de la República para comparar sus excelencias con la degeneración de otros del bando opuesto en la sección «Episodios de la epopeya española. Figuras y contrafiguras del drama», sección escrita por Pomponio Mela y que enfrenta, entre otros, a Indalecio Prieto con Calvo Sotelo, a Largo Caballero con Lerroux, etc.

Otras secciones habituales, sobre todo a partir de 1938, son la información sobre la escasez de alimentos o las dificultades de las viviendas, así como la titulada «Se desea conocer el paradero de ...», destinada a localizar a los desaparecidos. La información exterior ocupa un gran espacio a partir de 1938 en la sección «La situación internacional» y, en relación con España, en «España ante el mundo».

Pero la guerra también provoca en La libertad el desarrollo de la opinión sobre los acontecimientos bélicos y sobre las diferentes actitudes de los enfrentados, en una línea que mezcla la crónica cotidiana, el tono costumbrista, el denuesto al adversario y la recreación literaria. Ejemplos de ello son las «Postales del camino» de Zamacois, en los primeros meses de la contienda; las «Cartas de Levante», convertidas a finales de 1937 en $*$ Cartas de Barcelona», de Felipe; las «Cartas de Cataluña», de Hermosilla; o las «Cartas a ti» de Juan Verdades. Todas ellas recogen y aplican a las nuevas circunstancias históricas la técnica epistolar de Cadalso, si bien más apegadas que las de este al momento y al detalle cotidiano, pero sin que falte el ingrediente irónico.

Desde un punto de vista narrativo hay que destacar la experiencia de Antonio Montoro, que a partir de septiembre de 1937 alterna su producción poetica con las reseñas de teatro y de libros, la crítica literaria y el artículo de opinión en las secciones «La ruta de los ríos» y, sobre todo, las «Crónicas de poeta». En estas últimas predomina la crítica de líderes políticos pero también están presentes las referencias a las actitudes de pintores (Picasso), músicos (Falla) o actores de cine (J. Crawford). En estas semblanzas es frecuente que Montoro recoja algunos versos, propios o ajenos, que ilustran sus ideas sobre las figuras de que habla.

En esta misma línea, pero ya no adscritos a sección fija sino figurando como artículos sueltos podrían citarse las colaboraciones de Ángel Lázaro o Cansinos Assens. 
El periódico aprovecha cualquier declaración de nombres importantes para incorporarla a sus páginas como contribución particular a la causa amenazada: publica colaboraciones de Juan Ramón Jiménez, una carta de Einstein en defensa de la República y hasta un texto atribuido a Mussolini y titulado, sintomáticamente, «Dios no existe». Incluso trasvasa, anacrónicamente, un texto de Larra («La planta nueva o el faccioso») y lo aplica a la situación presente, tras asociar la figura de Fígaro con la de los defensores de la República (José Alsina publica en La libertad el artículo «Fígaro frente al fascismo»).

En sus páginas se recogen frecuentemente reseñas sobre manifiestos de intelectuales en apoyo y solidaridad con la República: Menéndez Pidal, Antonio Machado, Marañón, Pérez de Ayala, Juan Ramón Jiménez, la Alianza de Escritores Antifascistas, manifiestos de escritores argentinos y de intelectuales franceses, etc. Lógicamente las sesiones del Congreso de Intelectuales Antifascistas son cumplidamente reseñadas en julio de 1937.

La libertad, por consiguiente, como todos los periódicos de la epoca, aprovecha todas las formas de cultura como instrumento de combate en defensa de una causa y las lleva a sus páginas. Esto es especialmente cierto en una manifestación como es el uso, la utilización de palabras y actitudes de escritores de renombre en uno y otro sentido: Porque si recoge un elogio a Mola de Manuel Machado o si se critican los comportamientos de Arniches o de Julio Camba, también es lógico que se ensalce la actitud, y la obra al tiempo, de Valle-Inclán, Galdós, Antonio Machado o Benavente. En cambio, no disimula el diario la ironía y la ambigüedad en los abundantes artículos sobre Unamuno de los primeros meses de la guerra.

Pero son dos poetas los que se convierten en símbolo positivo de la defensa de la libertad y de la causa republicana: Alberti y Lorca. Del primero publica el diario reseñas sobre sus libros y de sus viajes, ponderando siempre su noble entrega y la alta calidad de su lírica.

Lorca, por su parte, se convierte en las páginas de este diario en un mito y en símbolo: desde una breve comunicación sobre el rumor de su asesinato el uno de septiembre de 1936 hasta la confirmación de la noticia el nueve del mismo mes, Lorca aparece como el poeta-víctima de unas ideas de libertad, como poeta-símbolo de la actitud a seguir por los intelectuales y por el pueblo, como ejemplo notorio de la barbarie fascista y como, en suma, «El poeta de España» (15 de febrero de 1937). De ahí que las páginas de este diario recojan la enorme cantidad de homenajes que se le dedican por los más variados organismos en forma de breves noticias.

La poesía también se había transformado en un arma de combate, en un instrumento ideológico desde fuera de las páginas de La libertad. Pero es el mismo desarrollo de la poesía publicada en y para el diario lo que confirma en 
sus páginas este fenómeno evidente producido en la guerra civil ${ }^{3}$ y no sólo por la cantidad abundante de poemas publicados en este periódico sino por el hecho mismo de desarrollarse ciertos fenómenos que indican a las claras el grado de oficialización que la poesía había alcanzado, bien destacado por Salaün. ${ }^{4}$

A este respecto es interesante constatar la importancia del concurso de poesías satíricas que el periódico abrió al público a partir del 18 de abril de 1937, junto con otro dedicado a las caricaturas. Las premisas previas del concurso, como intento de revitalización del arte y como propuesta de un arte y de una literatura que han de ajustarse a nuevas circunstancias históricas, a la knueva justicia y la nueva moral», son sumamente interesantes. Con ellas se trata de proyectar la cultura desde el pueblo y para el pueblo, se trata de concebirla como un instrumento de combate más y de proyectarla hacia la constitución de un orden social nuevo.

La poesía aparece como el mensaje de una manera de entender el mundo, como el instrumento más adecuado para «dar forma y expresión al pensamiento de la transformación española». El arte se desvincula así de una exclusiva función estética y pasa a constituirse en un pilar más de la sociedad venidera.

Se remarca así su no separación del momento o, más bien, se va más allá y se propende a situar el arte dentro de ese momento, dentro de un ambiente especial de cambio revolucionario. Desde sus características connotaciones, el arte y la literatura contribuyen al desarrollo y potenciación de la causa republicana.

Las bases del concurso no hacen sino subrayar estos cometidos: porque, aparte del indirecto acto de homenaje en memoria de Luis de Tapia, el «insigne coplero de Madrid» que había llevado a cabo el grueso de su obra poética en las páginas de La libertad, se hace necesaria la vinculación de poesía y espíritu revolucionario y un ambiguo «perfecto sentido moral»s.

${ }^{3}$ Mención aparte merece el espacio dedicado al teatro en las páginas de La libertad. A través del diario puede seguirse la situación del teatro estrenado, con las resefias de José Ojeda y de Antonio Montoro (desde obras menores hasta las obras de Lorca, la refundición de La Numancia por Alberti o el éxito del reestreno de Juan Jose). El periódico da a conocer la situación de los escenarios madrileńos y se publican entrevistas con los comediantes del momento, además de intervenir en la polémica teatral con artículos teóricos de gran interés: «Proyectos para un teatro sano del pueblo, por el pueblo y para el pueblow, «El Consejo Nacional del Teatro, el teatro nuevo y el de siemprex, «El teatro español y sus problemas*, todos ellos firmados por Juan Ojeda.

4 Salauln, S.: La poesfa..., op. cit., pp. 58 y ss. Cfr. también Calamai, N.: El compromiso de la poesía en la guerra civil española, Barcelona, Laia, 1979; Caudet, F.: Las cenizas del fénix, Madrid, Ediciones de la Torre, 1993, especialmente "La poesía española de la guerra civil: la zona republicana", pp. 437-464; y el número 148 (1993) de la revista Anthropos, dedicado a la Guerra civil y producción cultural.

s Pueden compararse estas palabras con los objetivos propuestos en Hora de España. Vid. Caudet, F.: ed. Hora de España (Antologia), Madrid, Tumer, 1975. 
Las normas del concurso serán repetidas reiteradamente en los días siguientes, hasta el 1 de mayo de 1937, fecha en la que se tenía previsto cerrar el plazo de admisión de originales. Pero la redacción del periódico se vio desbordada y tuvo que ampliar este plazo hasta el 27 de mayo. En esta fecha se publicó la relación de trabajos presentados al concurso con un total de 211 envíos, aparte de poemas «que por no ajustarse a las bases del concurso serán entregados al Jurado para que éste acuerde lo que sobre ellos considere más oportuno". Todo ello no hace sino testimoniar de manera harto evidente el momento de inflación poética que vive el país en estos momentos. Son poemas todos que, sin embargo, no se publicaron, con la excepción de tres de ellos y de los que solo se han conservado los lemas, por lo que es difícil opinar sobre su contenido: oscilan entre los homenajes a Luis de Tapia, las requisitorias antifascistas y la exaltación de fechas, lugares y héroes republicanos.

En cualquier caso, el 22 de julio se reunió un jurado formado por Alberti, Altolaguirre y Antonio Aparicio y declaro desierto el premio, si bien lo dividio entre José Serrano de la Lastra, por su poema «Al charlatán o charlista García Sánchiz, fascista» (que se publicará el 24 de julio) y Jose Vargas Ataurique por su poema «El arroz» (publicado el 25 de julio), recomendando además otros cuatro títulos de los cuales sólo se publicará uno, el de Luis García de los Ríos, «Los de la quinta columna» (16 de septiembre de 1937). Pero se incumplió el cuarto punto que estipulaba dar «a conocer otras poesías recibidas, algunas de carácter serio y otras de carácter militar, escritas por soldados de las trincheras». El comentario de Salaün es acertado:

Estos casos ejemplares revelan hasta que punto el fenómeno poetico, individual y colectivo, puede desbordar la misma prensa y erigirse en auténtico fenómeno social ${ }^{6}$.

Pero en el caso de La libertad es más evidente, para constatar el momento de abundancia poética que vive el país, la oficialización de la poesía y su interpretación como arma ideológica, la existencia de secciones poéticas. Y esto simplemente porque, a la par que se eliminan o quedan muy desdibujadas todo tipo de secciones de corte circunstancial y superficial (ocio, sucesos, deportes), la poesía no cesa sino que se mantiene y se incrementa incluso respecto a etapas anteriores. Estas secciones poéticas confirman una vez más que la poesía es también un arte en armas que contribuye a la creación de un orden social nuevo y justo.

- La poesía de la guerra..., op. cit., p. 60. 
En La libertad se trata de secciones poéticas personalizadas y la mayoría de los poemas publicados en el periódico durante la guerra son obra de dos autores: Luis de Tapia y Antonio Montoro.

El primero prosigue en la guerra sus ya famosas «Coplas del día» aunque introduciendo novedades respecto a sus versos de antaño, y publica un total de 89 poemas (uno de ellos repetido dos veces) entre el 18 de julio de 1936 y el 13 de abril de 1937. Montoro, por su parte, publica en La libertad 109 poemas repartidos en sus dos secciones poéticas: los «Romances de retaguardia» (entre el 24 de febrero de 1937 y el 3 de marzo de ese mismo año) y, sobre todo, los «Romances de La libertad» (entre el 3 de abril de 1937 y el 28 de febrero de 1939). Si la sección de Tapia es diaria en los primeros meses de la guerra y ocupa su lugar fijo en la primera página del periódico, las de Montoro saldrán más espaciadas y en distintos lugares del diario.

El resto de poemas se reparten entre nueve autores más: Ortiz de Pinedo, José Serrano de la Lastra, José Vargas Ataurique, Luis de los Ríos, José Villarroel de Ancos, Agraz, Cayhuela y dos poemas anónimos, aparte de un fragmento de un poema de Agraz.

El total absoluto comprende, por lo tanto 207 poemas y un fragmento, repartidos de la siguiente manera: 87 en 1936; 70 en 1937, 46 en 1938, y 4 en 1939. La distribución por meses es como sigue:

1936 Julio: 13 poemas de Tapia.

Agosto: 26 poemas de Tapia.

Septiembre: 26 poemas, 25 de Tapia y 1 de Ortiz de Pinedo.

Octubre: 22 poemas de Tapia.

Noviembre: no se publican poemas.

Diciembre: no se publican poemas.

1937 Enero: no se publican poemas.

Febrero: 6 poemas, 1 de Tapia y 5 de Montoro.

Marzo: 4 poemas de Montoro.

Abril: 14 poemas, 11 de Montoro, 2 de Tapia y 1 anónimo.

Mayo: 7 poemas de Montoro.

Junio: 3 poemas de Montoro.

Julio: 6 poemas, 4 de Montoro, 1 de Serrano de la Lastra y 1 de Vargas Ataurique.

Agosto: 9 poemas, 8 de Montoro y 1 anónimo.

Septiembre: 9 poemas, 8 de Montoro y 1 de Luis de los Ríos. Octubre: 3 poemas, 2 de Montoro y 1 de Villarroel. 
Noviembre: 7 poemas, 6 de Montoro y 1 de Agraz.

Diciembre: 2 poemas de Montoro.

1938 Enero: 8 poemas de Montoro.

Febrero: 8 poemas de Montoro.

Marzo: 1 poema de Montoro.

Abril: 9 poemas, 8 de Montoro y 1 de Cayhuela.

Mayo: 7 poemas de Montoro.

Junio: 6 poemas de Montoro.

Julio: 4 poemas de Montoro.

Agosto: 2 poemas de Montoro (y un fragmento de Agraz)

Septiembre: no se publican poemas.

Octubre: 1 poema de Montoro.

Noviembre: no se publican poemas.

Diciembre: no se publican poemas.

1939 Enero: 2 poemas de Montoro.

Febrero: 2 poemas de Montoro.

Marzo: no se publican poemas.

Así contemplada, en cuanto a la cantidad se refiere, la distribución temporal de los poemas de La libertad se aparta un tanto de la evolución poética trazada por Salaün en su obra básica. No sucede lo mismo desde un punto de vista externo, ya que estos poemas permiten constatar los dos hechos más característicos de la producción poética en la zona republicana: diversidad métrica y estrófica pero absoluto predominio del romance y del octosílabo. Más de la mitad de los poemas de La libertad se acogen, en efecto, al molde rítmico del romance, al que contribuye sobre todo Montoro con sus versos.

El romance de Montoro se atiene siempre a una estructura métrica idéntica: un estribillo de tres versos asonantados (de diferentes medidas pero siempre de arte menor) que se repite cuatro veces, y tres tiradas de octosílabos en forma de romance de doce versos cada una. Es el molde rítmico empleado por Montoro en todos sus poemas excepto en cuatro ocasiones: en «Las colas» ( 25 de abril de 1937) s6́lo escribe dos tiradas de octosílabos; en "Voz de mando" (30 de enero de 1939) suprime los estribillos; y en «La voz de un viejo poeta» (15 de febrero de 1939) las tiradas de octosílabos son cuatro y de 24 versos cada una, aparte de la desaparición del estribillo. Son casos todos, como se ve, de modificación ligera de su esquema habitual. Sólo en un poema, el titulado «Invocación a Margarita Xirgu» (31 de enero de 
1939) deja de lado el romance para escribir en un verso y estrofa de carácter más culto: serventesios en alejandrinos, con un total de quince estrofas.

De esta forma, el romance consigue un claro predominio, sometiéndose además a la serie de asonancias conocidas más utilizadas históricamente. Los romances de Montoro registran las siguientes asonancias: á-o (17 veces), á-a (15 veces), é-o (13), é-a (12), á-e (11), 6-a (10), 6-o (9), ú-o (4), í-a (7), é-e (4), o-e (4), i-i (2), i-e (1).

Tambien utilizarán el romance en este periódico Agraz, Cayhuela, el autor anónimo que publica el «Romance de Córdoba resucitada» y el autor anónimo de «iAy que pena!»

Serrano de la Lastra, Vargas Ataurique y Luis de los Ríos utilizan el verso octosílabo combinado a voluntad con otros versos de arte menor; Villarroel emplea el alejandrino en estrofas de cuatro versos con rima consonante en los pares, quedando el último de la serie encadenado; y Ortiz de Pinedo el soneto, con cambio de rima en los dos cuartetos y tercetos ABACBC.

Luis de Tapia maneja una mayor variedad de estrofas y versos: combina octosílabos y tetrasílabos con rima consonante a voluntad, escribe poemas en versos hexasílabos o tetrasílabos, rimando en consonante a voluntad, mezcla pentasílabos y decasílabos u octosílabos y pentasílabos o utiliza un serventesio dodecasilabo.

Pero a pesar de este intento de creación de estrofas nuevas mezclando metros más conocidos, Tapia se centra sobre todo en estrofas tradicionales, preferentemente de arte menor. $Y$ así, aunque escribe dos sonetos, su predilección se orienta hacia moldes estróficos de carácter más popular: utiliza en varias ocasiones el romance, agrupados los octosílabos en series de cuatro versos, o el romancillo, los pareados diversos y la seguidilla. Se sirve mucho también de la copla, octosilábica o tetrasilábica, con rima consonante normalmente, y de la cuarteta de verso octosílabo, heptasilabo o hexasilabo.

Frente al predominio absoluto de la asonancia en los otros poemas de La libertad, los de Tapia tienden hacia la rima consonante, utilizada en estrofas, como la copla o la seguidilla, tradicionalmente asociadas a la rima asonante.

El ritmo es muy regular y apenas si se notan errores en el cómputo métrico. Las excepciones no son reveladoras, por su escasez extrema. Así en el romance de Montoro «José Miaja», del 28 de abril de 1937:

El general se ha dormido.

Entre sueños rememora:

«En el Jarama los tigres, en el Brihuega las marmotas». 
Más raro aún es encontrar errores en la rima, pero Montoro escribe en «Luis de Tapia» (16 de abril de 1937):

\author{
Callad un momento. ¿Corre \\ por la campiña el Cefiro? \\ el azul claro del Grecia \\ torna más azul el día.
}

y para conseguir la medida exacta se emplean con corrección las sinalefas, las diéresis y sinéresis, los hiatos y todos los artificios de que disponen los poetas para alcanzar aquella: la conciencia poética se manifiesta en la no realización, a veces, de la sinalefa para escribir en el metro deseado.

Pero si, con el fin de combatir toda tendencia a la diseminación, la estrofa y aun el verso tienden a ser estructuras cerradas y acabadas, con un predominio claro de la esticomitia sobre el encabalgamiento (como advierte Salaün, para quien «la aparición de los encabalgamientos significa ya una distancia formal respecto de la práctica colectiva convencional» ${ }^{7}$ ), La libertad muestra, de un lado, este hecho en los poemas de Tapia y lo matiza en el de Montoro, ya que este autor se encuentra a medio camino entre el poeta popular y el escritor que maneja formas más cultas y distanciadoras. Por eso, Montoro acude muchas veces al encabalgamiento, con conciencia estética, como en el poema publicado el 29 de abril de 1937, «La heroína»:

\author{
El fusil está brunido \\ de limpieza y engrasado \\ para la terrible lucha \\ contra el maldecido fascio. \\ La muchacha es de vanguardia \\ y camina sorteando \\ los peligros. El fusil \\ es ahora un ser humano. ${ }^{8}$
}

Si en la consecución de un ritmo regular los poemas publicados en $\mathrm{La}$ libertad son representativos de la poesía republicana de la guerra civil, también lo son por la utilización de una serie de recursos poéticos que tratan de

7 Ibid., p. 292.

- A veces, sin embargo, el verso se convierte en el mismo Montoro en una unidad tan clara que puede recoger famosas consignas, como «Les enfants de la patriew, en el poema publicado el 27 de abril de 1937. 
potenciar su significado de arma de combate y su sentido de exaltación de la causa popular. Uno de ellos es, sin duda, el uso frecuentísimo de los signos gráficos, como mayúsculas, puntos suspensivos, exclamaciones, etc. En Luis de Tapia, por ejemplo, es raro el poema en el que no se halle una estrofa con signos de admiración o de interrogación retórica y un final en puntos suspensivos.

A veces parece arbitrario su uso y, desde luego, harto abusivo, ya que Tapia se admira por todo: por las virtudes de su pueblo en armas, por las iniquidades de los enemigos, por la necesidad de ropa en las trincheras o por la favorable situación de los frentes; y utiliza un sistema de prolongación de la estrofa que nada tiene que ver con los usos ortográficos normales.

Lo que ocurre es que ambos procedimientos no son sentidos como gratuitos sino que tratan de plasmar los sentimientos del poeta en un momento histórico especial o pretenden contagiar el entusiasmo propio a los lectores potenciales: la admiración y los puntos suspensivos se convierten de esta forma en una señal de admonición; lo signos ortográficos traducen en el plano escrito el sentimiento que el autor quisiera hacer común y general a todos sus lectores y a todo su pueblo; son, así, un medio de expresión ideologica más.

En este sentido es de destacar también el empleo continuo por Tapia y por Montoro de los procedimientos anafóricos, de la repetición de palabras y de esquemas sintagmáticos, de los paralelismos, de las enumeraciones, los quiasmos y las estructuras binarias y hasta de los procedimientos de correlación de miembros, con el claro objetivo de que «se perciban las cosas en términos de evidencias, de verdad imperiosa». 9

Los ejemplos que podrían aducirse serían innumerables y bastará citar algunos casos significativos. El sentimiento de exaltación y de intento de afirmar una verdad y hacerla sentir como necesaria se consigue en muchos poemas de Tapia por medio de la repetición anafórica, unida a la enumeración y al paralelismo. Un ejemplo muy claro lo constituye su famoso poema « No pasarán!», del 21 de julio de 1936:

¡Ni el facioso capitán, ni el regular musulmán, ni el que paquea en desván, ni el señorito holgazán, ni el banquero gavilán.

* La poesta de la guerra..., op. cit.... p. 295. 
El procedimiento tiene un sentido similar en Montoro, si bien este lo utiliza de manera menos frecuente, por ejemplo en el poema «Zaragoza inquieta», del 22 de agosto de 1937:
Hay que arrojarlos al río
a todos los hombres negros, por negociantes, por vagos, por canallas, por soberbios, por ser hienas africanas, por insensibles, por necios, por ambiciosos, por rudos, por cobardes traicioneros, por no tener corazón, ni finura ni cerebro, por haber vendido a España a déspotas extranjeros.

En Montoro es más frecuente el paralelismo sintagmático en estructuras que persiguen la intensidad emotiva, como en el poema publicado el 2 de marzo de 1937, «Guardería infantil»: «murí su madre en el pueblo/ su padre cayó en el campo»; y, sobre todo, la repetición de palabras como un intento de fijación momentáneo de sucesos y actividades: a este respecto es significativa la repetición en muchos de sus romances de los gerundios y otras formas verbales. Por ejemplo, en «La ciudad rota» (3 de marzo de 1937): «En plena Puerta del Sol/ renace el Moloch fenicio,/ que va tragando, tragando/ las mujeres y los niños».

Si los procedimientos formales y las técnicas retóricas de escritura se utilizan en función de un rendimiento ideológico concreto, como se observa con claridad en los poemas de la guerra y en los que nos ocupan, la poesía utiliza todo tipo de ingredientes conceptuales para servir a la causa republicana. Toda, o buena parte, de la tradición histórica o literaria es movilizada con este fin.

En los poemas de Tapia se alude, como intento de comparación o de contraste, de ironía o de simple ejemplaridad a Ortega, a Unamuno, a Marañón, y también a Séneca, a Calderón. Y utiliza la figura del Cid para compararla con desventaja para ella con las de los héroes republicanos en "¡Valencia!" ( 4 de agosto de 1936):

¡El Cid, según mis noticias,

al lado de estas milicias

El Cid era un infeliz! 
y compara la lucha de la Reconquista (contra los musulmanes) con la guerra que vive en esos momentos España (8 de agosto de 1936, «Regulares»):

\author{
¡No triunfarán en las lizas \\ moros de tan ruin calaña! \\ ¡Pues no les dimos palizas \\ a los moros en España!
}

No sólo en la historia de España se buscan paralelismos de situaciones presentes sino que se va más allá de las fronteras para explicar, en su historia, la solidaridad de la Unión Soviética (recordando el episodio del «Potenkin», 1 de agosto de 1936) o se denuncia la actitud de neutralidad de Francia e Inglaterra, comparándola con la Francia de Danton y la Inglaterra de Cromwell:

\author{
¿Para tal resultado \\ vio su cuello Danton guillotinado? \\ ¿Qué diŕa Danton \\ si hoy viese abandonada a mi nación? \\ ¿Y Cromwell, el inglés \\ quiso que Albión hoy diera este traspiés? \\ ¿Qué diría Oliverio \\ si hoy viese abandonado al pueblo ibero?
}

Se sirve también Tapia de la leyenda de Santiago para ironizar sobre las actitudes de los cristianos y rememora los periodos anteriores de guerras civiles para declarar que esta vez, por fin, triunfarán la razón y la justicia:

No importa; era fuerza que el tiempo viniera de arreglar el pleito por siempre jamás.

¡A la guerra todos! ¡Será la postrera!

¡Y saldrá una España: Una y nada más!

Toda la historia se pone en funcionamiento para declarar la etapa decisiva que vive España, y se contrasta su pasado oscurantista con la luz de un mañana venturoso en el soneto «Alcázares» (23 de julio de 1936):

Aves doradas son de sangre grana,

en sus alas escrito va un mañana

y el Mañana al Ayer va a hacer pedazos. 
Las alusiones históricas y literarias se intensifican en los poemas de Montoro, que realiza alusiones por todos los campos de la cultura: alusiones a $\mathrm{Na}$ poleón, y a la revolución francesa, a César y a Nerón, a Pablo Iglesias y a Machado, a Ticiano y a la revolución mexicana, a Goya y a Cervantes, etc.

Montoro da un paso más allá y en sus poemas, con fines de contraste, de identidad, o de ejemplo, aparece todo el universo mitológico grecorromano: Edipo y la Esfinge, Atalanta, Pan y Cibeles, las sirenas, las Parcas, los cíclopes, Dédalo y el laberinto, Perseo y la Hidra, Baco y Júpiter, Plutón y las Euménides, Tetis y Peleo, las Harpías, y un largo etcétera en el que caben también la mitología egipcia y germánica y las leyendas y cuentos infantiles.

En ocasiones, la mitología sigue de cerca el desarrollo de la historia actual y sirve constantemente como punto de referencia. Es lo que sucede en «La Cibeles enterrada» (29 de junio de 1937), poema en el que Montoro va y viene de la realidad cotidiana de los bombardeos de Madrid, que hacen necesaria la protección de sus monumentos, a la recreación mitológica. En otros casos, la mitología es el puente de encuentro entre dos situaciones históricas, como en «El abrazo imposible» (2 de junio de 1937): frente a la reconciliación pretérita, simbolizada en el abrazo de Maroto y Espartero, la situación actual hace imposible el abrazo, como lo es el potencial de la Venus de Milo del Louvre.

Esta mitología de los poemas de Montoro se ve acompañada de un, en ocasiones, léxico rebuscado que hace obligatoria su separación de los poetas más populares y, por supuesto, de Tapia: palabras como bicéfalos, protervos, ufania, pindárico, nereidas, estentóreo, eutrapélico, ubérrimo, etc. testimonian el intento de Montoro de levantarse a un nivel distinto del popular.

Montoro también echa mano de las alusiones literarias para llegar al fin ideológico pretendido y no sólo por su recreación de célebres paginas de nuestra literatura (como el capítulo del Quijote sobre el discurso de las armas y las, que se funden ahora en las «Brigadas Internacionales», 11 de septiembre de 1937) o por su empleo de personajes literarios, como Ginés de Pasamonte, sino también con versos precisos de Manrique (14 de abril de 1937) o de Rubén Dario (4 de abril de 1937):

«Sangre de Hispania fecunda

de nuevo a torrentes mana.

Así se defiende un pueblo:

Madrid dicen que se llama. ${ }^{10}$

10 La «Canción del jinete» de Lorca resuena como eco en el «Romance de Córdoba resucitada», de autor anónimo, publicado en La libertad el 1 de agosto de 1937. 
para no hablar de palabras de himnos («Les enfants de la patrie», de «A vuestros brazos», 27 de abril de 1937) y esquemas tanto formales como ideológicos del folclore hispánico, presentes sobre todo en el uso del estribillo por parte de Montoro pero también en la forma y en el contenido de los poemas de Tapia, que hace alusiones a la canción de Mambrú (14 de agosto de 1936) o recrea el verso de «La Virgen del Pilar dice» (27 de julio de 1936).

No obstante, la producción poética que se recoge en La libertad, como es de rigor en la poesía republicana de este periodo, se caracteriza, a veces, por su pretendido intelectualismo, por su flexibilidad ideológica y por su total dominio de los poetas copleros, Tapia y Montoro. Dos figuras que se diferencian, sin embargo, por muchos rasgos formales, como los examinados, y por la configuración ideológica de sus versos.

Tapia es, con Agraz, el coplero por excelencia, el autor de comentarios poéticos cotidianos sobre los asuntos del momento, como se señaló en La libertad el 15 de febrero de 1937, cuando se daba por concluida su producción poética en un artículo titulado «El poeta de Madrid»:

Luis de Tapia fue por antonomasia el poeta de Madrid y el poeta de la libertad. Su copla, siempre generosa de amor y de justicia, ha sido en lo que va de siglo, el comento feliz de todo acontecimiento [...] Parece imposible que en Madrid ocurra algo que Luis de Tapia deje sin comentar.

Antes de comenzar la guerra, Tapia había sido fundamentalmente eso, un autor que comentaba con gracia, ironía y crítica social, los acontecimientos del día.

La libertad realiza una semblanza del poeta el 13 de abril de 1937 con ocasión de su muerte en la que se destaca su colaboración constante en la prensa: «Luis de Tapia, el poeta del pueblo por antonomasia, era también el poeta del periodismo». Había comenzado su labor de periodista y coplero en 1914 en El Imparcial, y en 1918 pasó a la redacción de La libertad, además de ser diputado en las elecciones a Cortes Constituyentes. Con su obra contribuyo, dice el perídico, «no poco al descrédito de un sistema político deshonrado desde su nacimiento» y, por esto, es considerado como un poeta de la prerrevolución:

Cada hora tiene su poeta y Luis de Tapia fue el poeta de la prerrevolución. El, con su pluma, que a veces era estilete fino y otras cuchillo tajante, puso al desnudo la verdad española sobre la estampa sin fondo de su Madrid goyesco. 
Es por eso por lo que Salaün considera que Luis de Tapia «simboliza la presencia estatuaria del discurso poético en la prensa y en la práctica política» ${ }^{11}$ desde mucho antes de la guerra. $\mathrm{Y}$ al poder integrarse fácilmente su obra anterior en este momento histórico se pregunta además Salaün por el papel desempeñado por el autor en el movimiento poético de la guerra, habida cuenta de que lo esencial de su producción se encuentra en julio y agosto de 1936:

Tapia lanza el Romancero incluso antes que los organismos políticos y militares, a partir de una técnica poética a la vez sencilla y eficaz, basada en el humor, la gracia, un entusiasmo nunca agresivo, una lengua popular sabrosa y ritmos fáciles a pesar de su diversidad. ${ }^{12}$

Pero al llegar la guerra, desde los primeros días de julio, la poesía de Tapia se pone al servicio de la causa republicana y su verso es, más que nunca, verso aplicado, verso de configuración e intención ideológica en defensa de la justicia y la verdad populares. Si la copla del día 18 de julio aboga por el olvido de las penas cotidianas, la correspondiente al 19 de julio es ya una declaración de la necesidad de defender la República todos juntos:

Todos juntos en un haz y en apretado montón dando al peligro la faz con sereno corazón.

Esta solidaridad en defensa de la República es una constante en los versos de Tapia. Y el verso se torna instrumento de combate y desde él se sirve la ideología hacia fuera y hacia dentro. Tapia escribe poemas que responden a una necesidad de preparación para la guerra y para vencer (como en «Hay que hacer» o en «Firmes»), aunque pide paciencia a los que continuamente reclaman actitudes de combate en sus «ofensivas de café». El poema más representativo desde este punto de vista es «Adelante», publicado el 15 de febrero de 1937 y en el cual se insta sucesivamente al republicano, al socialista y a los miembros de los sindicatos a que contribuyan a la victoria:

¿En pie y en marcha constante que en ello el vencer se encierra y es decisivo el instante!

"La poesía de la guerra..., p. 321.

12 Ibid., p. 323. 
Desde la poesía se pretende implicar en la defensa de los ideales republicanos a otras naciones democráticas («Obreros del mundo,/ ¡ayudad a España!/ ¡A la España libre,/digna y proletaria») a la vez que se exalta la actitud de las naciones que apoyan la España libre, sobre todos la Unión Soviética («Mujer rusa», 18 de septiembre de 1936, y «Noble Rusia», 13 de octubre de 1936) y Méjico («Gracias», 10 de octubre de 1936).

Y con la poesía se pretende introducir el espíritu de la ayuda a los combatientes en el ánimo de los ciudadanos. Tapia escribe una serie de poemas de contenido evidentemente utilitario. En «Aviadores» (16 de agosto de 1936) se da apoyo a los trabajadores que arreglan las averías de los aviones, y en «Ole el Ayuntamiento» se equipara la valentía en los frentes y el trabajo de la retaguardia:

\section{¡La guerra no es vanguardias únicamente! \\ ¡Detrás hay tanto lucha como en el frente!}

Se da la gracias por los envíos de víveres de los pueblos pequeños ( $\alpha$ Envíos», 27 de agosto de 1936) y en varios poemas el verso aplicado se ocupa de la necesidad de mandar ropa al frente (así en «Ropa al frente», «Insisto» o «Ropa de abrigo»).

El carácter ideológico del verso y su aspecto utilitario se observa también en algunos poemas de Tapia que hacen ver la necesidad de la unión política entre todos los partidos republicanos.

¡Pero no hay caso, amigos,

en guerra y paz,

todos los «anti el fascio»

forman un haz! ( $\ll$ No es guerra civil», 23 de agosto de 1936).

Estos versos dan o pretenden transmitir una idea de la unidad republicana ya que sólo así se podrá ganar la guerra y establecer un nuevo orden social más justo y libre.

Pero Tapia, a diferencia de algunos poetas fascistas ${ }^{13}$, que llevan a cabo una exaltación de la guerra y de la muerte, no hace la alabanza de ellas sino de la vida y de la paz, como en «Batallón de la vida» (13 de agosto de 1936) o

13 Cfr. Caudet, F.: «Aproximación a la poesía fascista española: 1936-1939», Bulletin Hispanique, LXXXVIII (1986), pp. 155-189. 
«Los niños» (14 de agosto de 1936) y, sobre todo, en «Canción infantil» (24 de septiembre de 1936), poema en que la emoción se pone al servicio de un intento de racionalización de la justicia:

\author{
Padre, ¿Has matado mucho? \\ ¡No hablemos del morir! \\ ¿Y mi pan? ¡Ahí lo tienes! \\ Tu hambre ha dado fin \\ ¿Y el jardín? ¡El futuro \\ ya es para ti un jardín!
}

La muerte, en todo caso, se presenta como un riesgo que merece la pena afrontar por los desposeídos del mundo (En «Desfile», 20 de octubre de 1936, se puede leer: «Peor no han de vivir;/ por eso hay que pensar/ que no van a morir/ ¡van a resucitar!»)

Este utilitarismo se integra así en un poesía como comentario de hechos cotidianos: las noticias que vienen de los frentes («De los frentes», «Seguidillas bélicas», «Dum-dum») o la salutación al nuevo gobierno en «Salud», 5 de septiembre de 1936, poema que aparece rodeado, en la página que se publica, de las fotos de los miembros del nuevo gabinete ministerial.

De la misma manera, se apega el poema, a veces, a la circunstancia histórica en el retrato del enemigo: se describe con tenues pinceladas, y siempre con notas negativas, a los generales rebeldes (Mola, Queipo de Llano, Cabanellas, Franco) sin renunciar al humor en las descripciones, como la alusión a la afición a la bebida de Queipo de Llano, y los juegos verbales con su nombre, y a los fascistas en general: «Los facciosos lo hacen todo/cual sabeis entre dos luces»; sus consignas (sobre todo el "Arriba España», del que se hace una divertida burla en el poema *iArriba* del 4 de septiembre de 1936) y, sobre todo, la opresión que significa su doctrina, como en $\ll_{i}$ En pie!» (11 de septiembre de 1936) que toma como punto de partida unas famosas palabras de «Pasionaria».

Este mundo de opresión, de esclavitud y de intolerancia es vinculado por Tapia a la doctrina cristiana. Muchos poemas tocan de lado este tema o lo ocupan por entero, desde el famoso «iNo pasarán!» del 21 de julio de $1936\left(\varkappa_{i} N i\right.$ el mitrado, ni el deán,/ni el cura, ni el sacristán,/no pasarán!»)

Se censura con acritud la actitud y pensamiento del Papa frente al conflicto hispano y se compara a aquellos con la supuesta toma de contacto del problema por Jesucristo en « $i$ Que hable don Pío», y lo mismo ocurre con los obispos («iQué diría»). Se presenta a Santiago como «el tonto de Clavijo» por haber ayudado - juega Tapia y se burla de la leyenda medieval- a los miembros de una clase contra los árabes, los mismos que ahora se alían con 
los moros para arrasar España (en «Caballeros de Santiago», 22 de agosto de 1936), y va más allá, oponiéndose a la idea de que «Dios esta con ellos», y oponiéndose al mismo Dios si, de existir, fuera verdad en «Ya salió aquello», del 2 de septiembre de 1936:

\author{
¡Pues os diré, enemigos, \\ aca, inter nos, \\ que Madrid no lo toma \\ ni el mismo Dios!
}

No es extraña la presencia de versos de este estilo en un perídico que publicaba el 15 de octubre de 1936 una contrarréplica a los diez mandamientos, entendida como «decálogo del madrileño frente a las audacias del fascismo y la invasión morisma».

El mismo apego a la circunstancias históricas se aprecia en su intento de llevar ánimos a los defensores de Madrid, sobre todo en «De madrugada», en el que se mezcla lo trágico de los bombardeos con la expresión chusca de burla del enemigo fascista.

Pero si en todos estos aspectos el poema se centra en la circunstancia histórica determinada, hay muchos otros en que se tiende a una expresión más abstracta y a un evidente distanciamiento del acontecimiento concreto. Esto es especialmente cierto en los poemas en que se exalta al protagonista de la lucha, de la epopeya, un protagonista no individual sino colectivo. El 1 de agosto de 1936 Tapia exalta la figura de Mangada en «El general Serrano" pero, normalmente, se va hacia lo colectivo: la lucha de todos en defensa de la República, las mujeres proletarias, los milicianos anónimos y ahistoricos, los héroes anónimos («Quinto Regimiento», 5 de agosto) y los trabajadores que reparan los aviones, los marineros, los tranviarios, los médicos y enfermeras, y el pueblo sin más especificaciones: «No hay más que pueblo..../o demás es nada».

El individuo en los poemas de Tapia ha dejado de tener el protagonismo y el autor lo ha transferido al pueblo, un pueblo que se siente dominador de su destino y empeñado en la instauración de un orden social nuevo que acabe con las injusticias. El maniqueísmo es, en este aspecto, inevitable, como en tantos otros poemas de guerra.

Muchos poemas de Tapia enfrentan dos ideas del mundo en una visión dialéctica que conducirá, de manera simple, a la victoria de Bien, de la Justicia, de la Libertad, asimilados siempre a la ideología republicana. La victoria de los ideales republicanos se ve como inevitable, y el orden viejo no puede volver ya: 
¡Son cosas las citadas

para siempre pasadas

y no pueden volver!

¡No, no, no puede ser!

¡No podemos perder!

(«No puede ser», 14 de octubre de 1936)

Otras veces, el viejo y el nuevo orden no se presentan con un sentido tan abstracto y se aboga por una revolución que acabe con la incultura y la miseria o que realice la reforma agraria («Hoy será el terreno/de quien lo cultive»).

Nada tiene de extraño que considere que un pueblo como este está realizando su epopeya liberadora, palabra que es Tapia, según Salaün, quien primero menciona, ya el 30 de julio de 1936 en el poema «Seguidillas bélicas» y posteriormente en otras poesías, como el titulado «Ayer y hoy»: «La epopeya se desliza/y el poeta va detrás" (15 de agosto de 1936).

Este poema trata precisamente de cómo ha variado la función del poeta con los nuevos artilugios bélicos, desplazando su antigua misión de animador de la causa. Ya en un poema del 26 de julio de 1936 consideraba Tapia que en momentos como los actuales la poesía debía dar paso a la acción (hecho que, sin embargo, desmiente su propia obra), y el 25 de octubre pedía «Silencio»:

¡Hoy el soldado

más útil es

que los poetas...

¡Silencio, pues!

Y, en general, en los poemas de Tapia, la voz del poeta tiende a confundirse con la masa, no llevando a primer término el yo lírico, la expresión individual, por lo que todos estos aspectos de su poesía debieron influir mucho en la producción poética de la guerra de España.

Pero las diferencias entre los poemas de Tapia y los de su sucesor en La libertad son evidentes. En Montoro, para empezar, se da una mayor conciencia de su ser de poeta y de las particularidades de estos. En sus versos el poeta, el artista, puede coincidir, y lo hace, con los ideales de su pueblo, pero su condición de poeta siempre aparece de múltiples formas. Unas veces, como en «Guardería infantil» (2 de marzo de 1937), el poeta se presenta como protagonista de la anécdota que da pie al romance. Otras veces, aparece como testigo de acontecimientos, como en «El tanque» (4 de mayo de 1937).

- La presencia del yo sentido como individualidad y no confundido con lo colectivo, frente a lo que sucede en tantos poemas de guerra, se une en el caso 
de Montoro a una reivindicación de la labor del poeta y de su importancia. Así en «Beligerancia» (1 de marzo de 1938) escribe:

\author{
Pero he de hablar. Los poetas, \\ si les halaga tal nombre, \\ cuando la sangre del pueblo \\ en caudal de ríos corre, \\ no callan, porque si callan \\ hay cobardía o temores. \\ He de hablar, decir mis versos, \\ cantar mis exaltaciones. \\ Jamás callaré mis ritmos \\ cuando se matan los hombres.
}

La labor del poeta es entendida por Montoro como carácter misional y, aunque en determinadas ocasiones alaba el arte proletario, como en «El perídico mural" (10 de septiembre de 1937), lo general es sentir la poesía como arte, arte vinculado a un fin ideológico pero producto de individuos escogidos. $Y$ así lo normal es que ensalce la figuras del poeta personal y genial, tomando como ejemplos a Tapia, Lorca o Machado.

Todo ello se explica por su idea del poeta, tal y como la expresó en un breve artículo sobre los romances de Agraz, publicado el 20 de agosto de 1938 en La libertad:

\begin{abstract}
Ahí está la verdad poética, una verdad que salta y sobrevive a todas las verdades. El hombre que sabe sentirla y expresarla de tal modo ya se sabe, hermano lector: Ese hombre es poeta. ${ }^{14}$
\end{abstract}

No sólo en la consideración de la poesía y de los poetas se diferencian Tapia y Montoro. Frente a aquel, los poemas de Montoro carecen totalmente de notas humorísticas y el comentario directo y sencillo es sustituido por una expresión a ratos metafórica y simbólica (la sangre, los tigres, los vampiros, etc.) que no excluye las alusiones constantes a las mitologías de diversas latitudes.

Estas mismas características explican tambien sus diferencias en el desarrollo temático. En Montoro disminuyen muchísimo, por ejemplo, las

14 Líneas más arriba habra escrito: «No es que sean las masas quienes dictan sus ritmos al cantor pero es el cantor quien interpreta el sentir de las masas y se produce así el prodigio de los poetas populares». 
alusiones al cristianismo, tan frecuentes en Tapia, y, siempre que aparecen, hay un especial interés por parte del autor en separar cuidadosamente a Cristo de los cristianos, como ocurre en «iQué triste papel!» del 17 de noviembre de 1937;

\author{
¿Cómo nombrar la dulzura \\ de una religión tan noble? \\ Y si resultan más fieras \\ que los otros estos hombres, \\ en vez de servir a Cristo, \\ satánicos servidores.
}

Disminuyen también, con relación a Tapia, los poemas que expresan directamente la lucha de clases, aunque esta aparece con veladuras en el trasfondo de exaltación de las clases populares y en algunos versos concretos, como en «Esclavitud» (10 de febrero de 1538): «Soy esclava, eres esclavo/pero la lucha redime:/o la libertad se alcanza/ o se muere por ser libre».

Y quedan reducidos al mínimo los poemas directamente utilitarios, aunque también de estos puedan citarse ejemplos: la necesidad de pan (17 de febrero de 1938) o la de luchar contra los mercaderes (14 de junio de 1938) y, por supuesto, la ropa contra el frío, como en «El lobo invierno» (2 de diciembre de 1937).

Pero no ocurre, como en Tapia, una exhortación directa a la acción sino que estos aspectos se encubren con una retórica de abstracciones y símbolos, en una arte elusivo que también se manifiesta en las descripciones de los enemigos, pues Montoro tiende a la abstracción y a la simbología animal y mitológica para designar al enemigo fascista, que es presentado como lobo, tigre, hiena, cuervo o como idéntico a las divinidades mitolológicas negativas.

Si Tapia atacaba directamente a los cabecillas de la sublevación militar, Montoro se contenta con aludirles como «hombres de la caverna», como fascistas y rebeldes, como bárbaros o como matricidas.

Algunas veces, sin embargo, se atreve a algo más y habla de las «viborillas de Falange» (6 de septiembre de 1937) o acusa a los «Aranda, Franco, Varela/tres apellidos malditos» ( 7 de enero de 1938) a la vez que dedica un poema a Franco, presentado como «verdugo/ de patíbulo y de cuerda» ( 1 de febrero de 1938), y otro a Yagüe. En todos estos poemas el maniqueísmo es feroz y se evidencia sin más comentarios en estos versos de «Luchamos por todos" (8 de abril de 1938):

Jugamos oro; ellos cobre;

somos manantial, son cieno; 
rubio trigo, ellos cizaña;

somos verdad, mienten ellos.

Esta misma característica de la abstracción, impensable en Tapia, se muestra también en Montoro en su presentación de la guerra. El rasgo difuminado es evidente en los poemas dedicados al asedio de Valencia, Alicante o a las batallas de Belchite, Brunete, Santander, Zaragoza, Teruel, etc. Todos estos poemas, una parte importante de la producción de Montoro, si están motivados por el hecho histórico concreto, se alejan de todo planteamiento historicista y rehúyen la crónica del acaecer cotidiano. Una separación del acontecimiento puntual y un ingreso en la abstracción que alcanzan su mejor respresentación en «La intrusa» (22 de abril de 1937), que presenta la guerra y la muerte en una tradición fácilmente detectable.

Ahora bien, Montoro, si es reacio al rasgo puntual, entra por el lado humano de la guerra y habla de los efectos de la aviación, y del arma mortífera que es el tanque, de los refugios y de la resistencia republicana, del trabajo en la guerra, de los niños muertos, de la imposible reconciliación.

Para Lechner, en la poesía de la guerra civil «no hay casi quejas acerca de lo que se sufre, de los que se echa en falta, ni de la vida absurda que impone la guerra» ${ }^{15}$. Esto no se puede aplicar al caso de Montoro, que dedica muchos romances a estos aspectos, precisamente:

Niños, he visto los niños destrozados por las fieras, mujeres, pobres mujeres yertas de sufrir, histéricas de tantos golpes fatales siendo yunque en la conciencia.

Cosas de horrible color, camarada, negras, negras.

(«Periodismo madrileño», 8 de mayo de 1938)

y que dedica algún otro a la defensa de Madrid, no en un sentido de crónica puntual sino en lo que tiene de efecto sobre la población y sobre la ciudad, como en «La Cibeles enterrada», pero siempre envuelto en ambiguiedades y alusiones históricas, literarias y mitológicas.

Junto a estas características, la poesía de Montoro publicada en La libertad muestra una considerable tendencia hacia el homenaje y hacia la nostalgia,

is Vid. Lechner, J.: El compromiso en la poesía española del siglo XX, Université de Leyden, 1968, p. 154. 
acelerada por las circunstancias exteriores de la propia guerra: Montoro realiza homenajes de escritores (Lorca, Tapia, Cervantes, Machado), de actores (Xirgu) y de hechos bélicos (Brunete, Belchite, etc.), exalta a la República en su aniversario y celebra el primer aniversario de la guerra y la fiesta de los trabajadores, aspectos todos conectados con el hecho de la guerra, lógicamente.

Junto a ello es inevitable la exaltación de las grandes figuras y héroes republicanos: Miaja, Durruti, Lister, Pestaña, Cipriano Mora y Azaña, junto al homenaje a Pablo Iglesias (en «La ruta del abuelo» del 9 de diciembre de 1937).

No obstante, como en el caso de Tapia, el héroe más celebrado por Montoro es el héroe anónimo, colectivo y popular: los soldados de las Brigadas Internacionales y los que se juegan la vida en la vanguardia, los médicos y enfermeras que curan el cuerpo y fortalecen el ánimo de los combatientes, los artilleros, los comisarios, los huérfanos, las mujeres que padecen con nobleza los horrores de la guerra, los tranviarios, los segadores, los periodistas, etc.

Montoro realiza en algunos poemas una defensa de la cultura y de la educación, como uno de los objetivos básicos de la revolución. Y así, si homenajea a los intelectuales antifascistas reunidos en Valencia ( 9 de julio de 1937), no es menos importante para él la consideración de los maestros-soldados, como en «Las milicias de Cultura» (15 de agosto de 1937):

\author{
Soldados, el corazón \\ lleva su ritmo al cerebro; \\ alli está la cera virgen \\ que plasma los pensamientos, \\ la palabra los expresa, \\ la pluma traza sus fueros. \\ ¡Guerra contra la incultura! \\ Soldados, al parapeto.
}

Junto a la cultura, Montoro elogia sobre todo el trabajo, como liberador del hombre y como fuerza capaz de destruir el viejo orden oligárquico y fundar una sociedad justa y libre. Es la esperanza revolucionaria:

Sangre derramada. El mundo

nos mira en estos instantes,

asombrado de que España

lleve al mundo por delante.

No defraudéis, compañeros,

estas horas delirantes.

(«Alianza de Juventudes», 27 de febrero de 1937). 
Esperanza en la que se implica a todos. El primer poema de Montoro publicado en La libertad el 24 de febrero de 1937, «Égloga», presenta al campesino unido a su tierra y al resto de los trabajadores para realizar la revolución y la victoria en la guerra, antesala imprescindible de aquélla. El pueblo está realizando su epopeya, una epopeya que terminará con la instauración de un orden democrático, antifascista y revolucionario. $Y$ epopeya que en los poemas de Montoro se constituye también en la clave del arco de su obra:

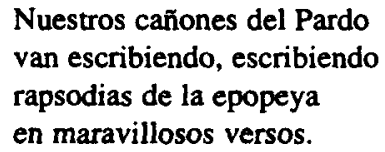

(«Cañones en el Pardo», 12 de febrero de 1938).

El resto de los poemas publicados en La libertad y cuyos autores no son Tapia ni Montoro, oscilan entre el homenaje, la comicidad y la sátira, la denuncia al espionaje y los denuestos contra la guerra y los fascistas. Pero todos ellos están comprometidos con una causa republicana y, en ocasiones, revolucionaria. Y para todos ellos la guerra ha significado un campo de experimentación poética, aunque no produjeran una poesía de ruptura pero sí fueran conscientes de la dimensión social y aplicada del verso y proyectaran sus ideas con voluntad racionalizadora y clarificadora del momento que vive el país.

Si la poesía política, como escribe Bowra, «cuenta tanto con la excitación y la explotación de las emociones, estas son para ella más importantes que la materia inteligible con la que se vinculan y el resultado es, a veces, el desacuerdo entre lo que se dice realmente y la energía con que se lo dice» ${ }^{16}$, los poetas de La libertad sometieron a la emoción la razón o, mejor, utilizaron la emoción humana para racionalizar una realidad histórica injusta y la búsqueda de un porvenir esperanzado. La emoción significó para ellos una posibilidad de utilizar contenidos que implicaran la realidad y la denunciaran.

16 Vid. Bowra, C.M.: Poesia y politica, Buenos Aires, Losada, 1961, p. 24. 